\title{
The tadpole of an insular population of Cycloramphus boraceiensis Heyer, 1983 (Anura: Cycloramphidae) with a review of larval descriptions for species in the genus
}

\author{
Gustavo Colaço ${ }^{1,2}$; Marcelo Batista ${ }^{1,3}$; Gabriel Limp ${ }^{1,4}$ \& Hélio Ricardo da Silva ${ }^{1,5}$ \\ 1 Universidade Federal Rural do Rio de Janeiro (UFRRJ), Instituto de Ciências Biológicas e da Saúde (ICBS), \\ Departamento de Biologia Animal. Seropédica, RJ, Brasil. \\ 2 ORCID: http://orcid.org/0000-0001-9861-1472. E-mail: gustavcolaco@gmail.com (corresponding author) \\ ${ }^{3}$ ORCID: http://orcid.org/0000-0001-7970-1931. E-mail: marcelokcsb@gmail.com \\ ${ }^{4}$ ORCID: http://orcid.org/0000-0002-5872-8833. E-mail: gabriellimp@hotmail.com \\ ${ }^{5}$ ORCID: http://orcid.org/0000-0002-1819-8110. E-mail: heliorsilva@gmail.com
}

\begin{abstract}
A literature survey for the external morphology of tadpoles for species in the genus Cycloramphus Tschudi, 1838, which is mainly represented by larval descriptions, resulted in finding some inconsistent character descriptions. In a few cases, some of the information is either not presented or mistakenly reported; in some cases, the illustrations provided the information not present in the descriptions. Here in we use a sample of tadpoles of an insular population identified as Cycloramphus boraceiensis, present a description for it, compare it to the original larval description for this species, and using it as a model, present a comparative review of the other larval descriptions for Cycloramphus tadpoles. We evaluate that most of the mistakes we found in the literature are associated to the unique morphology of these semiterrestrial larvae and some of their seemingly adaptation to their microhabitats, which for the majority of the known species is a film of water running associated to or near streams.
\end{abstract}

Keywords. Larvae; Literature-review; Flattened-Waterfall-Frog; Semiterrestrial; Terminology.

\section{INTRODUCTION}

Twenty-eight species are currently recognized for the genus Cycloramphus Tschudi, 1838. They are all endemic to the Atlantic Forest, on the eastern coast of Brazil (Verdade \& Rodrigues, 2003; Weber et al., 2011; Frost, 2020), with species recorded from the State of Bahia to Rio Grande do Sul (Heyer, 1983a; Haddad \& Sazima, 1989; Lingnau et al., 2008). Based on aspects of their natural history, reproduction, adult and tadpole morphology, Heyer (1983a) grouped these species into five phenetic groups, as follows: C. bolitoglossus, C. eleutherodactylus, C. fuliginosus, C. granulosus and C. ohausi groups. Additionally, using data for natural history (microhabitat of egg laying), reproductive and developmental biology of a few species, the genus has been alternatively arranged into two groups, as suggested by Verdade (2005), and followed in more recent publications (e.g., Lima et al., 2010; Nunes-de-Almeida et al., 2016; Verdade et al., 2019). These two groups were designed to contain the species with exotrophic separated from those with endotrophic tadpoles. By the time of this suggestion, the basic information for that was derived from publications by B. Lutz (1947, 1948), Heyer \& Crombie (1979), Heyer (1983a, b). More recently, this arrangement was followed, with due consideration for its tentative nature, by Brasileiro et al. (2007) when describing C. faustoi as indicated by the sentence, "tadpoles which are apparently endotrophic and hatch in advanced phases".

Species with exotrophic larvae deposit their eggs on the inclined surface of rocks, which are wetted by splashes from waterfalls, small rivers, or by water trickling from soaked soil above the exposed rock. In this group, tadpoles thrive on films of water on the same rock faces where eggs are deposited (Heyer, 1983a; Verdade et al., 2019). The concept of a group of endotrophic larvae was developed based on data gathered for Cycloramphus stejnegeri by Heyer \& Crombie (1979). They reported a female, under a log near a stream, carrying 40 early stages larvae on its back (Gosner, 1960 stages 30 and 31), with a large amount of yolk within 
them. Based on that, and morphological descriptions and comparisons with Zachaenus parvulus tadpoles (see Heyer \& Crombie, 1979), they inferred a terrestrial mode of development, an idea that was later followed and expanded by Verdade \& Rodrigues (2003), Verdade (2005), and Brasileiro et al. (2007).

Most of the knowledge on larval morphology in the genus was gathered for species with exotrophic tadpoles, perhaps because they are easier to find, usually in the same spots that the adults are found. For the 28 recognized species of Cycloramphus, only ten have tadpoles known and described: C. bandeirensis Heyer (Verdade et al., 2019), C. boraceiensis Heyer (Heyer, 1983a), C. brasiliensis (Steindachner) (Heyer, 1983a), C. fuliginosus Tschudi (Heyer, 1983a), C. izecksohni Heyer (Heyer, 1983a), C. lithomimeticus Da Silva \& Ouvernay (Da Silva \& Ouvernay, 2012), C. lutzorum Heyer (Lima et al., 2010), C. rhyakonastes Heyer (Nunes-de-Almeida et al., 2016), C. stejnegeri (Noble) (Heyer \& Crombie, 1979) and C. valae Heyer (Heyer, 1983b).

Even with such a relatively small number of known larvae, our investigations revealed that the morphological descriptions for these larvae need to be amended by the acquisition of more information. Therefore, we propose to re-evaluate the morphological descriptions of Cycloramphus tadpoles based on illustrations presented in the original descriptions, added to our observations of additional specimens. We hope to call attention to the need to standardize and improve the morphological descriptions for these larvae, as has been already proposed for some other tadpoles (e.g., Schulze et al., 2015; Haas $\&$ Das, 2010). In part, the morphological misinterpretation we found may result from the unusual morphology of these tadpoles when compared to more common, pond-dwelling, Type IV larvae as presented by Orton (1953) and Starrett (1973). We focused on reviewing the larval morphology of $C$. boraceiensis, correcting and expanding some of the data originally presented by Heyer (1983a). This species has populations recorded along the oceanic slopes of the Serra do Mar, between Rio de Janeiro and São Paulo and on two continental islands, one in the State of São Paulo, and the other in the State of Rio de Janeiro (Heyer, 1983a; Bittencourt-Silva \& Silva, 2013; Rocha et al., 2018).

When Heyer (1983a) originally described the larvae of this species, he had pointed out the occurrence of populations of Cycloramphus boraceiensis from Boracéia and Ilha de São Sebastião, São Paulo and from Paraty and Ilha Grande, Angra dos Reis, Rio de Janeiro. However, the tadpole description was based on a single specimen (Fig. 1), at stage 42 from Boracéia, State of São Paulo. Our evaluation of Heyer's (1983a) description revealed problems ranging from the proper determination of the larval stage to a few misinterpretations of morphology. Heyer (1983a) identified the described tadpole (USNM 217933) as Gosner stage 42 , but in a subsequent paper the same material is presented as [about] stage 40 (Heyer et al., 1990). In both works, however, the illustration of the tadpole shows a tadpole on an earlier stage (the forelimbs have not yet emerged, and the mouth has not experienced the major reconfiguration indicative of the stages 40 or 41 ). In addition, some important and more recently described characters, which may be unique to Cycloramphus tadpoles were either not reported (e.g., vent tube, spiracle, meniscus) nor presented with a proper detailed information (e.g., abdominal flap). This situation compelled us to engage in this revision.

Herein, we present a redescription of the tadpole of Cycloramphus boraceiensis based on semaphoront samples from Ilha Grande, Angra dos Reis, Rio de Janeiro. We present new characters and reinterpret previously described ones. Furthermore, we provide a comparison between the new data gathered and that of Heyer (1983a), and data gathered from the literature for other tadpoles of Cycloramphus. As a side note, it has been suggested that Cycloramphus boraceiensis may represent a complex of species, based on DNA sequences and cytogenetic information for distinct populations from São Paulo and one from Rio de Janeiro, (see Noleto et al., 2011; de Sá et al., 2019). We are aware that the described population of Cycloramphus boraceiensis larvae is indeed away from the species type locality. Nevertheless, this is not a problem, since our main purpose is to review morphological characters used for tadpole description. If the analyzed specimens are recognized in the future as a new species, our efforts are not invalidated, and only a taxonomic status update should be needed.

\section{MATERIAL AND METHODS}

The Cycloramphus boraceiensis tadpoles described were collected in Cachoeira da Longa, Ilha Grande (S230.'16.1", W44¹8'33.3" datum WGS84), Angra dos Reis, Rio de Janeiro. The sample was housed at the Herpetological Collection of Laboratório de História Natural, Anatomia Comparada e Sistemática de Anfíbios, Universidade Federal Rural do Rio de Janeiro (RU-GIR 69). Developmental stages of the tadpoles were determined using Gosner (1960). Comparisons of external morphology among our sample and other described tadpoles were made based on literature (see table 2).

The external morphology was described based on the study of nine tadpoles (at seven different stages). The morphological terminology and measurements follow Altig \& McDiarmid (1999) and Altig (2007), the measures are: Total Length ( $\mathrm{TL})$; Body Length $(\mathrm{BL})$; Body Maximum Height (BMH); Body Maximum Width (BMW); Eye Diameter (ED); Eye-Nostril Distance (END); Eye-Snout distance (ESD); Interorbital Distance (IOD); Intra-Nasal Distance (IND); Tail Length (TAL); Tail Maximum Height (TMH); Dorsal Fin Length (DFL); Ventral Fin Length (VFL); Dorsal Fin Height (DFH); Ventral Fin Height (VFH); Dorsal Fin-Body Distance (DFBD); Ventral Body-Fin Distance (VFBD); Snout-Spiracle Distance (SSD); Oral Disc Width (ODW). Other information about the cycloramphid tadpole morphology that we considered relevant was added based on recent Cycloramphus tadpoles' descriptions. The measurements were taken with a digital caliper, in millimeters, with the precision of $0.01 \mathrm{~mm}$ and are listed 
Table 1. Measurements of the tadpoles of (ycloramphus boraceiensis (Columns). Each line represents a measured specimen and its Gosner (1960) stage, respectively.

\begin{tabular}{|c|c|c|c|c|c|c|c|c|c|c|c|c|c|c|c|c|c|c|c|}
\hline Stage & TL & BL & BMH & BMW & ED & END & ESD & IOD & IND & TAL & TMH & DFL & VFL & DFH & VFH & DFBD & VFBD & SSD & ODW \\
\hline 29 & 20.75 & 5.06 & 1.88 & 3.11 & 0.61 & 0.64 & 1.56 & 1.14 & 0.63 & 15.49 & 1.33 & 7.61 & 8.01 & 0.33 & 0.39 & 7.78 & 8.1 & 2.88 & 1.77 \\
\hline 29 & 8.17 & 4.57 & 1.62 & 2.73 & 0.58 & 0.52 & 1.29 & 0. & 0.59 & 1. & 1.18 & 7.23 & 6.4 & 0.21 & 17 & 1.4 & 19 & 61 & 1.61 \\
\hline 30 & 21.55 & 5.39 & 1.92 & 3.01 & 0.73 & 0.73 & 1.67 & 1.3 & 0.12 & 16.19 & 1.19 & 8.93 & 8.8 & (3. & 0.34 & .37 & 7.72 & 3 & 2.11 \\
\hline 31 & 22.82 & 5.8 & 2.04 & 2.97 & 0.68 & 0.74 & 1.78 & 1.37 & 0.83 & 16.83 & 1.25 & 857 & 9.35 & 0.24 & 0.31 & & 7.74 & 3.37 & 1.98 \\
\hline 32 & 25.44 & 6.33 & 2.06 & 3.65 & 0.72 & 0.88 & 1.8 & 1.22 & & 19.55 & 1.61 & 10.48 & 10.29 & & & & 7.44 & 69 & .28 \\
\hline 32 & 23.41 & 5.95 & 2.14 & 3.11 & 0.7 & 0.82 & 1.8 & 1.39 & 0.79 & 17.26 & 1.39 & 9.36 & 9.93 & 0.28 & 0.36 & 7.85 & 7.44 & 3.54 & 2.08 \\
\hline 34 & 25.27 & 6.75 & 2.36 & 3.52 & 0.7 & 0.91 & 2.3 & 1.75 & 0. & 18 & 1.74 & 11.49 & 10.58 & 0.29 & 0.37 & 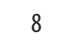 & 8.81 & 3.78 & 2.02 \\
\hline 36 & 32.95 & 7.18 & 2.33 & 3.87 & 0.95 & 1.06 & 2.49 & 1.85 & 1.04 & 25.4 & 1.95 & 14.8 & 13.88 & & 0.4 & 10.85 & 11.4 & 4.35 & 2.49 \\
\hline 44 & 31.84 & 7.77 & 3.39 & 3.74 & 1.1 & 0.95 & 1.37 & 2.52 & 0.82 & 23.85 & 1.98 & 15 & 12.42 & 0.23 & 0.36 & 9.98 & 11.26 & - & - \\
\hline
\end{tabular}

Total Length (TL); Body Length (BL); Body Maximum Height (BMH); Body Maximum Width (BMW); Eye Diameter (ED); Eye-Nostril Distance (END); Eye-Snout distance (ESD); Interorbital Distance (IOD); IntraNasal Distance (IND); Tail Length (TAL); Tail Maximum Height (TMH); Dorsal Fin Length (DFL); Ventral Fin Length (VFL); Dorsal Fin Height (DFH); Ventral Fin Height (VFH); Dorsal Fin-Body Distance (DFBD); Ventral Body-Fin Distance (VFBD); Snout-Spiracle Distance (SSD); Oral Disc Width (ODW).

in Table 1. The description presented is based on a tadpole at stage 36 , however all perceived variation is also considered. For the illustrations, a specimen at stage 36 was photographed in a stereomicroscopic Leica M205C equipped with multiple focus imaging software Leica Application Suite.

Because only one species of Cycloramphus is attributed to Ilha Grande, and the tadpoles were collected at the same spot where we observed calling adults and recent metamorphosed, we tentatively (see justification above) assumed these larvae to be semaphoronts of $C$. boraceiensis (RU 9593, RU 9594, RU 9687, RU 9688). In addition, the similarity to the information presented by Heyer (1983a) and Heyer et al. (1990) supports our decisions. Our identification was also supported by comparison of our sample to a single specimen assigned to C. bo-
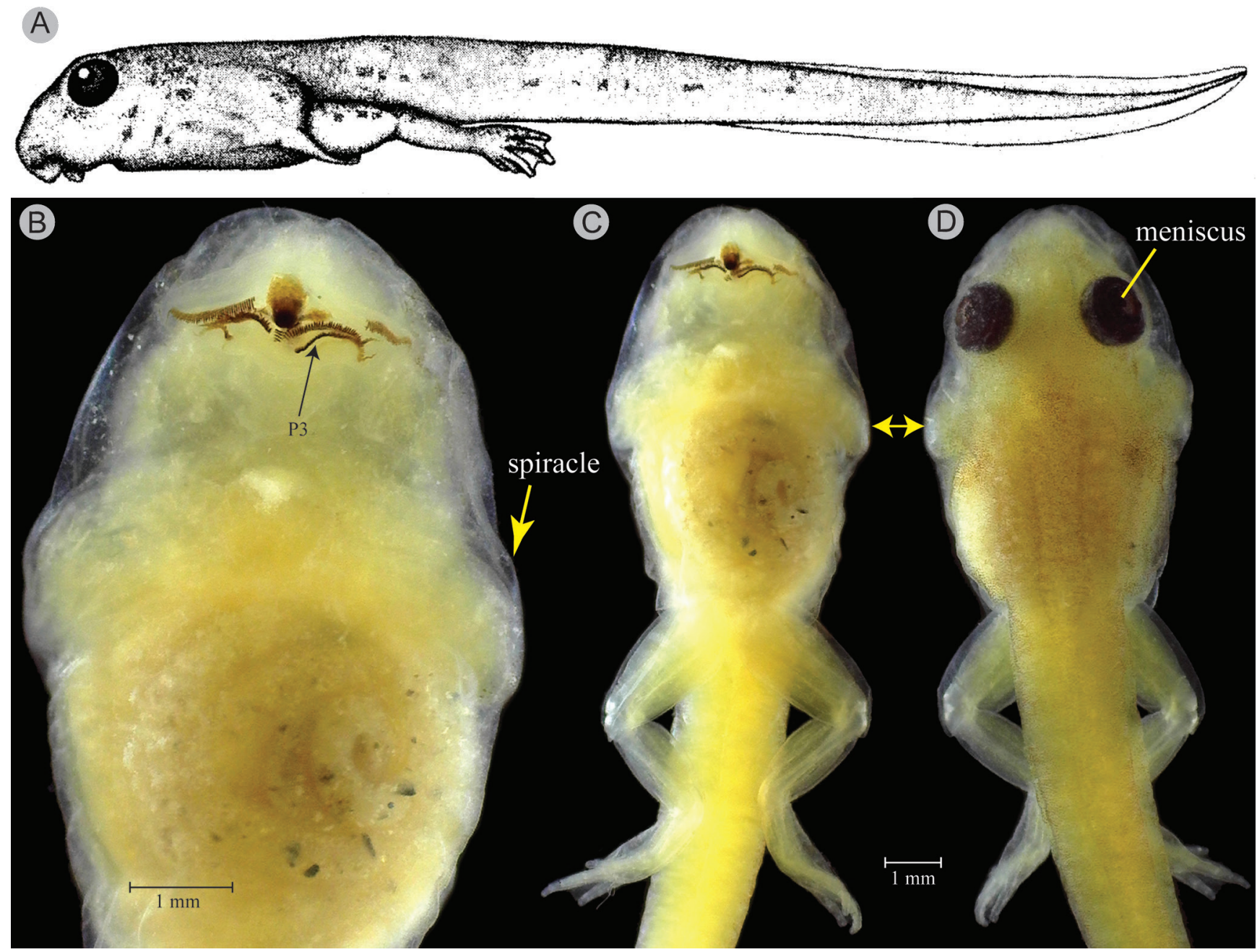

Figure 1. The tadpole of Cycloramphus boraceiensis (USNM 217933), from Estação Biológica de Boracéia, São Paulo, Brazil. (A) Illustration of the lateral view as originally appeared in Heyer's (1983a) original description, (B) and (C) ventral view and (D) dorsal view of the photographed specimen used in the original description and Illustration presented in A. We highlighted the P3 row, which is made up by smaller keratodonts than the other rows, the spiracle, meniscus, and the bulge on the gill region, that together with the degree of development of the feet are indicative of a tadpole Stage 41 (Gosner, 1960). 
raceiensis from State of São Paulo (CFBH 36944). Adult identification was based on the original description, on a key presented by Heyer (1983a), and comparison to specimens from Ubatuba, São Paulo (RU 9624, RU 9625, RU 9626, RU 9627).

\section{RESULTS}

\section{The tadpole of Cycloramphus boraceiensis}

\section{External Morphology}

The tadpole (Fig. 2; Stage 36) is elongated, the body is depressed, in lateral view, head and body elliptic in dorsal view, longer than wide. The abdominal region (head not included) is emarginated by a continuous flat fold of skin that forms the abdominal flap; its larger projection extending from the posterior half of the body, extending backward from the spiracle, laterally, covering partially (or entirely, depending on the stage) the hind limb buds and the vent tube, showing a shallow bilobed posterior margin. The vent tube is medial, short, conical and fused ventrally to the abdominal flap. Eyes dorsal and oriented dorsolaterally, approximately $10-14 \%$ of body length, bearing a distinct meniscus on upper iris. Snout rounded, nostrils oriented dorsolaterally, small, rounded and positioned about half the distance eye-snout. Spiracle single, sinistral, opening directly on the body wall, without an external tube, aperture nearly circular, oriented posteriorly in lateral view and posterolaterally in ventral view. Intestine coiled, the center of which is away from the center of the body to the left side. Oral disc ventral, not emarginated, almost as large as the head anteriorly; anterior gap in papillae occupy almost the entire anterior margin of lip, which may have no, one, or two notches; marginal papillae in single row, lacking submarginal papillae, lateral papillae larger than posterior papillae; posterior papillae alternating each other. Labial Tooth Row Formula (LTRF) is 2(2)/3(1), keratodonts on P3 noticeably smaller than those in the other rows; jaw sheaths chisel-shaped, laterally compressed, with serrate margins; upper jaw sheath projecting over lower sheath, fitting into rounded gap in mid A2 when mouth is opened. Lateral lines not visible. Tail long, muscular, about $3 / 4$ of total length, height anteriorly similar to body, myomeres evident; tail fins low, comprising about posterior half of the tail length. On the muscular tail, dorsally, where fins are absent, a thin gutter is observed where myomeres from both sides meet.

In life, body is dark brown dorsally, and pale brown laterally, with bright white and green iridophores scattered through the body dorsal and laterally. Color pattern on tail is similar, but with bright pale beige scattered ocelli-like spots. Ventrally, the body and tail are unpigmented and translucent, such that the developing robust abdominal muscles ( $M$. rectus abdominis), intestines and front limbs are visible. In preservative $5 \%$ formaldehyde after initial fixation in $10 \%$ solution), after a few months, iridophores are not evident and overall beige coloration on body is paler, however the pattern of spots remains similar to that in life.

Few external characters showed ontogenetic changes in our sample. In tadpoles at stage 29 , the meniscus is already present, but only after stage 34 it covers the lens (Fig. 2G). In our unique metamorphic semaphoront, at stage 44, the meniscus presents its largest size, covering a significant part of lens, the vent tube is not present anymore, and the abdominal flap is reduced to two lateral folds of skin on the inguinal region. Besides, at this stage, a long tail, with fins still present, membranes are present between the toes, in a pattern similar to that of adults, and the dorsal color pattern is already similar to that of adult specimens.

\section{Larval Biology and Natural History}

The larvae of Cycloramphus boraceiensis are considered semiterrestrial (sensu Altig \& Johnston, 1989; McDiarmid \& Altig, 1999) inhabiting inclined or almost vertical rock-outcrops near streams and small waterfalls (Fig. 3A, B). This microhabitat is permanently wet and covered by a thin film of flowing water that spills from the river itself or is maintained by splashes from a waterfall in areas shaded by the forest canopy. Tadpoles move about in this habitat by crawling and wiggling their bodies and tails, remaining almost entirely covered by the running film of water, but with the eyes above the water. Although speculative, it seems that the tadpoles adhere to the rock surfaces by taking advantage of superficial water tension (Fig. $3 \mathrm{C}$ ), and that is somehow improved by the expanded abdominal flap. Also, it appears they use the mouthparts to adhere to the rock surface (one can feel their bites when tadpoles are placed on the palm of their hands). Based on non-quantified information, the tadpoles were seen feeding and moving more actively during the day than at night, at the same areas where adults are seen calling at night. No more than three tadpoles were observed together on the same spot on a rock. The general color pattern is cryptic with the rock substrate.

\section{Analysis of the tadpole of Cycloramphus boraceiensis originally used by Heyer (1983a)}

Heyer (1983a) used the single specimen (USNM 217933) to describe the tadpole of Cycloramphus boraceiensis. We obtained digital photos of this specimen that were sent to us by the collection manager of the Smithsonian Institution. Overall, the specimen is in a poor state of preservation, and this did not permit observing most of the features one can get from freshly preserved specimens. However, from the images, we were able to infer that it is a tadpole at stage 41 (Fig. 1), as evidenced by the observation of toes with developed tubercles and interdigital membrane, and the elbows thrusting against the lateral skin of the gill chamber wall in dorsal and ventral views. A meniscus is present on the dorsal margin of the iris, a sinistral spiracular aperture is present, and fins are only present at about the posteri- 


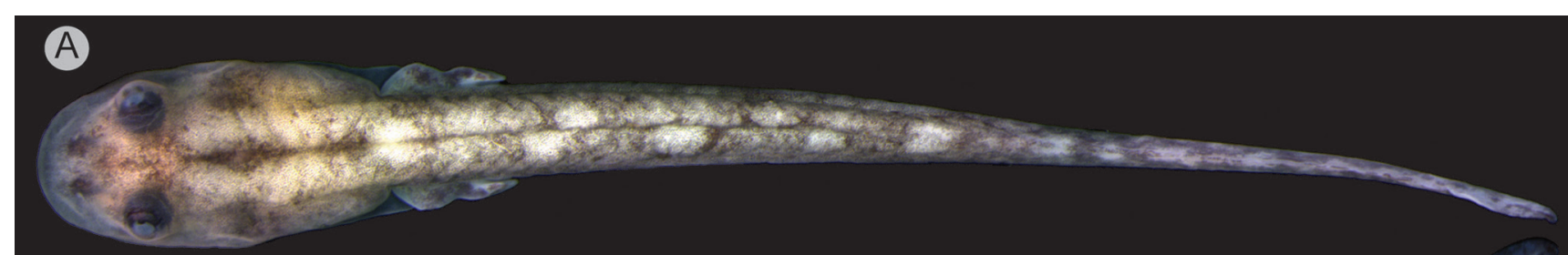

B

C 2.
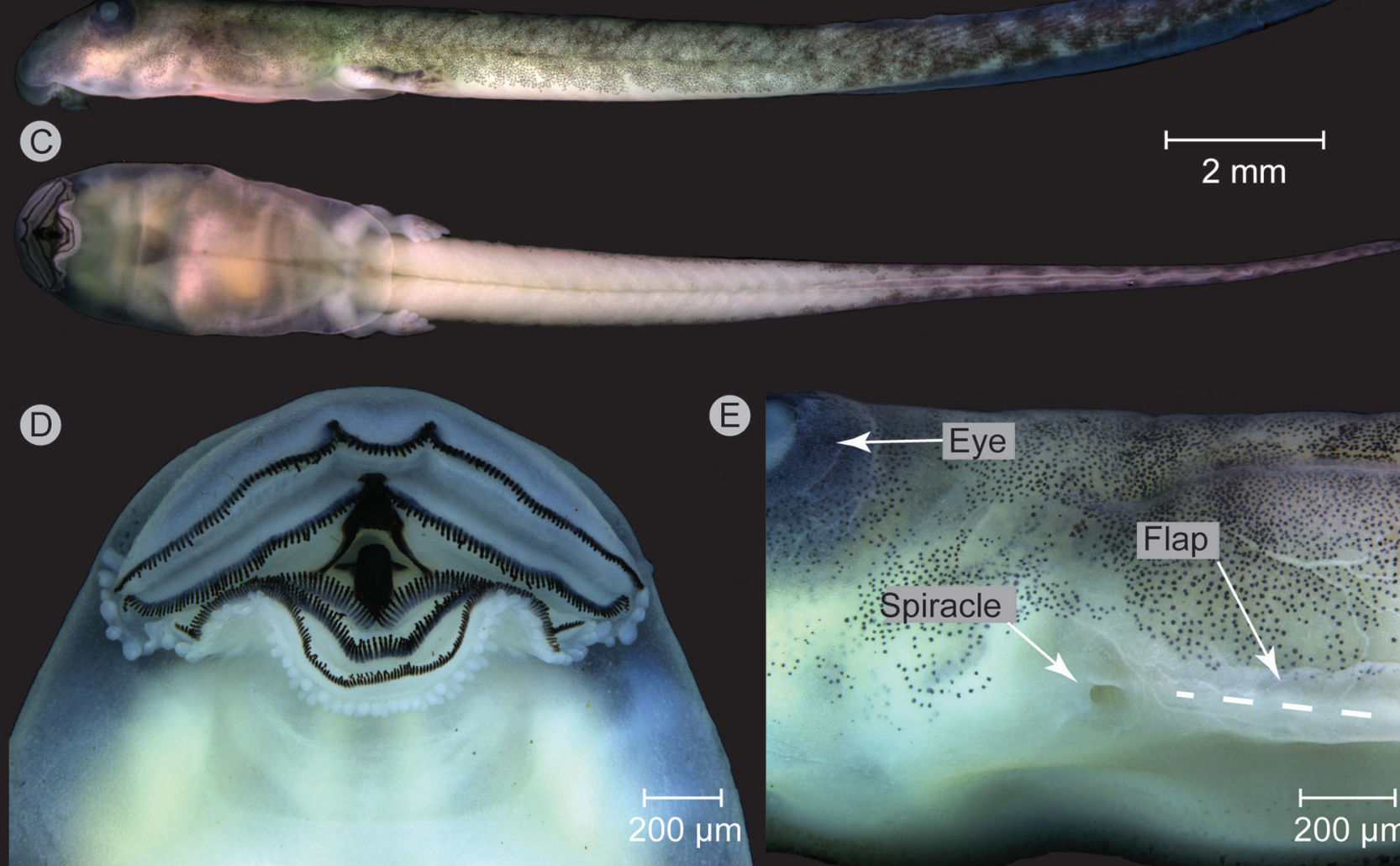

E

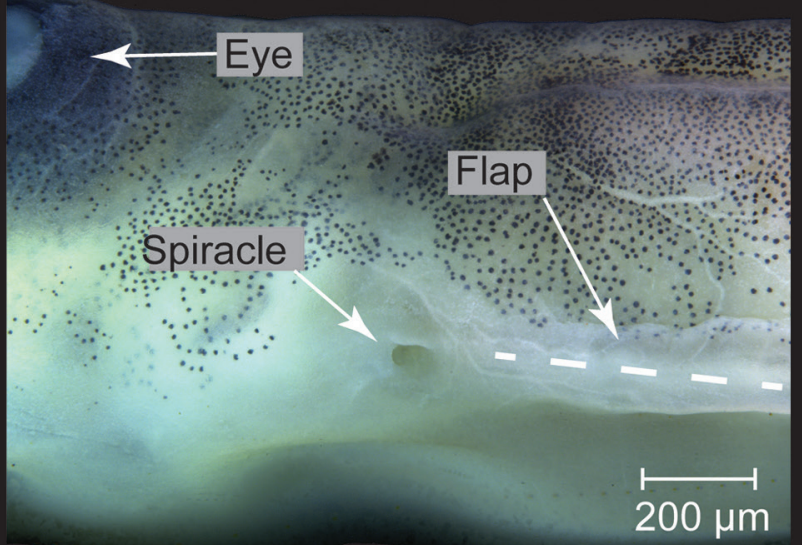

F

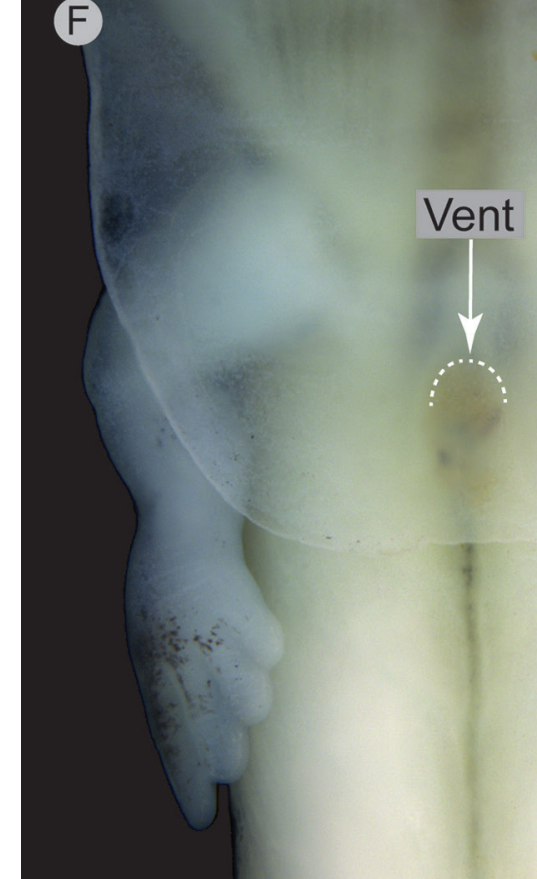

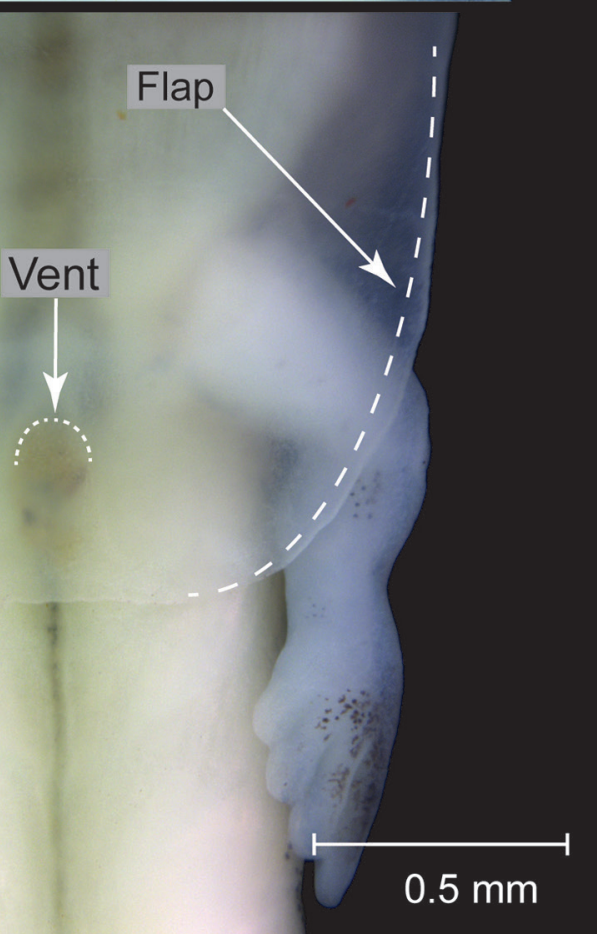

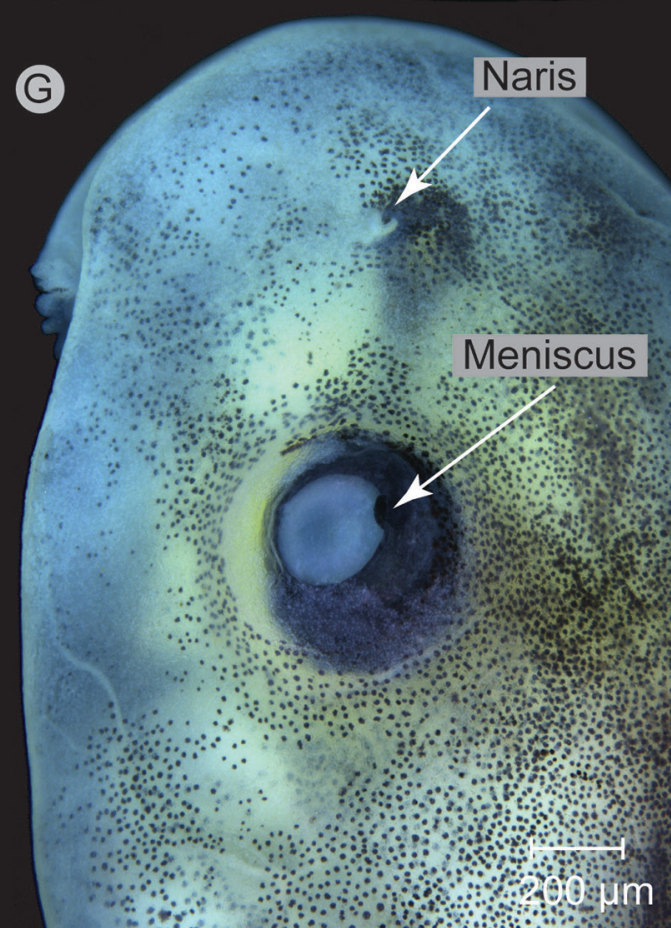

Figure 2. External morphological features of a tadpole of Cycloramphus boraceiensis Stage 36 (Gosner, 1960). (A) Dorsal view, (B) Lateral view, (C) Ventral view, (D) close up of oral disc and jaw sheaths; note the smaller size of keratodonts on P3 row, (E) close up of midbody showing spiracle opening and lateral view of the flap, (F) close up of the posterior portion of the body showing the position of the vent opening (the brownish coloration s fecal matter) and the extension of the flap, (G) close up of left side of the head. 
or-half of the tail. The oral disc and the papillae are poorly preserved, but a chisel-shaped jaw sheaths and series of keratodonts rows missing several elements are still preserved. Although the abdominal flap is present, it is not easy to observe it from the photos.

\section{Comparison with Larvae of Other Species of Cycloramphus}

The descriptions of the tadpoles for different species of Cycloramphus indicate that they are morphologically similar, yet little information about phenotypic and ontogenetic variation is available, making it difficult to use their morphology for species diagnoses (Lima et al., 2010; Nunes-de-Almeida et al., 2016; Verdade et al., 2019). A summary comparing morphological traits for all known larvae is presented in Table 2. Tadpoles of C. boraceiensis differ from $C$. brasiliensis and $C$. lithomimeticus by having a shallow bilobed abdominal flap; the flap is deeply bilobed in the latter two. The absence of gap on P1 in C. fuliginosus, C. lutzorum and C. rhyakonastes distinguishes these three tadpoles from C. boraceiensis. The tadpole of $C$. izecksoni differs by the relative position of the nares, which are closer to eyes. In C. bandeirensis the nares are instead closer to snout. Cycloramphus boraceiensis differs from C. valae by its eye diameter, which is proportionally (relative to body length) larger than in C. boraceiensis (although we did not take into consideration stages of development). Lastly, C. stejnegeri has the most distinctive tadpole from C. boraceiensis. Tadpoles of $C$. stejnegeri have a reduced and bilobed abdominal flap, in addition to differences in larval mouthparts (papillae and keratodonts); LTRF $2(1,2) / 2(1)$ and the spiracle is absent (but see discussion). We refrain from using morphometrics for diagnostic comparisons because, properly done, this would require data from across developmental stages to estimate comparative allometric curves, and collecting such data was not possible due to the small sample size.
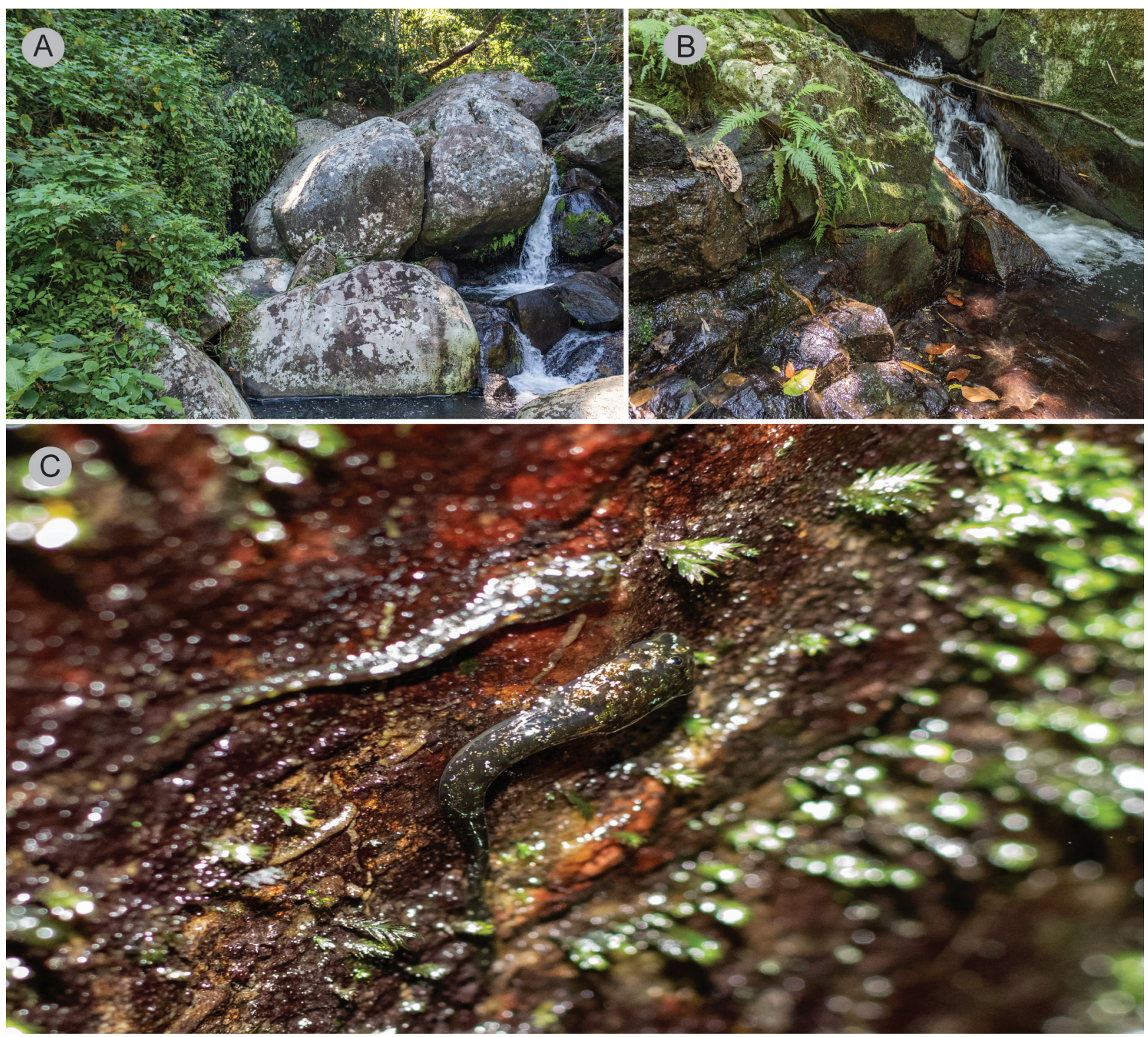

Figure 3. Aspect of the river on the beach of Longa, at llha Grande, Angra dos Reis, Rio de Janeiro. (A) An overview of the macrohabitat, (B) detail of the mesohabitat, and $(\mathrm{C})$ close up of microhabitat were tadpoles of Cycloramphus boraceiensis are found. 
Table 2. Reviewed and modified version of the Table first presented by Lima et al. (2010) compiling the main characters for external morphology of tadpoles of species in the genus Cycloramphus. Data took from original descriptions, except for C. boraceiensis from Heyer et al., (1990) and C. stejnegeri from Heyer, (1983a).

\begin{tabular}{|c|c|c|c|c|c|c|c|c|c|}
\hline Species & Stage & $\begin{array}{l}\text { Total length } \\
(\mathrm{mm})\end{array}$ & $\begin{array}{l}\text { Body length } \\
\text { (\% of TL) }\end{array}$ & $\begin{array}{l}\text { Eye diameter } \\
\text { ( } \% \text { of } \mathrm{BL} \text { ) }\end{array}$ & $\begin{array}{l}\text { Position } \\
\text { of nares }\end{array}$ & $\begin{array}{l}\text { Abdominal } \\
\text { Flap }\end{array}$ & $\begin{array}{l}\text { Ventral } \\
\text { tail fin }\end{array}$ & LTRF & Source \\
\hline C. boraceiensis & $29-44$ & $18.17-32.95$ & $21-26$ & $10-14$ & halfESD & SB or not & posterior half & $2(2) / 3(1)$ & Present study \\
\hline C. boraceiensis* & 41 & 27.2 & 23 & 18 & - & - & - & $2 / 3$ & Heyer, 1983a \\
\hline C. boraceiensis ${ }^{* *}$ & 41 & 26.5 & - & 14 & 一 & 一 & posterior half & $2(2) / 3$ & Heyer et al., 1990 \\
\hline C. bandeirensis & $26-42$ & $11.5-24.7$ & $20-28$ & $13-21$ & closer to snout & not visible/SB & $\begin{array}{l}\text { along tail, posterior } \\
\text { half, posterior third }\end{array}$ & $\begin{array}{c}2(2) / 2(1) 2(2) / 3(1) \\
2(2) / 3(1,3) 2(2) / 3(1,2,3)\end{array}$ & Verdade et al., 2019 \\
\hline C. brasiliensis & 41 & 37.5 & 25 & 17 & - & Bilobed & posterior half & $2 / 3(1)$ & Heyer, 1983a \\
\hline C. fuliginosus & 41 & 43.5 & 19 & 12 & - & - & posterior half & $2 / 3$ & Heyer, 1983a \\
\hline C. izecksohni & 41 & 32 & $23-28$ & 13 & - & SB or not & posterior half & $2 / 3$ & Heyer, 1983a \\
\hline C. lithomimeticus & $30-37$ & $19.6-24.3$ & $25-31$ & 16 & - & Bilobed & posterior half & $2(2) / 3(1)$ & Da Silva \& Ouvernay, 2012 \\
\hline C. lutzorum & $36-43$ & $26.2-26.9$ & $23-31$ & $15-20$ & halfESD & SB or not & posterior half & $2(2) / 3$ & Lima et al., 2010 \\
\hline C. rhyakonastes ${ }^{* * *}$ & 25 & 22.4 & 24 & 15 & halfESD & SB or not & posterior half & $2 / 3$ & Nunes-de-Almeida et al., 2016 \\
\hline C. stejnegeri & $30-31$ & 25.2 & 30 & - & - & Bilobed & along tail & $2(1,2) / 2(1)$ & Heyer \& Crombie, 1979/Heyer, 1983a \\
\hline C.valae & 36 & 29.3 & $24-29$ & $16-19$ & - & SB & posterior half & $2(2) / 3(1)$ & Heyer, 1983b \\
\hline
\end{tabular}

$\mathrm{TL}=$ Total length; $\mathrm{BL}=$ Body length; $\mathrm{SB}=$ Shallowly Bilobate; $\mathrm{ESD}=$ Eye Snout Distance. ${ }^{*}$ Classified originally as stage $42 .{ }^{* *}$ Classified originally as about stage $40 .{ }^{* * *}$ Illustration shows a tadpole at stage 31.

\section{Morphological misinterpretation and Improper Use of Terminology Associated to Tadpoles of Species of Cycloramphus}

Our survey of the literature resulted in the identification of a series of morphological misinterpretations associated with the descriptions of tadpoles of Cycloramphus. These may refer to errors in reporting observations or not reporting features that are present in anuran larvae in general and in Cycloramphus. We also found erroneous use of anatomical terminology and inconsistencies in stage determination. Some of these errors were replicated in follow-up publications and also include improper citation of information presented in the original descriptions. To facilitate the presentation of this material, we organized it as presented below, by characters.

\section{Terminology indicative of relative position of body parts}

It is not uncommon when describing fins, which are shorter in tadpoles of species of Cycloramphus, to use terminology that indicates the relative location of the structure. Therefore, using "distal" for referring to the relative position of the fins, which is only at the tip of the tail. The term "distal", used to refer to the position of dorsal and ventral fins, appears in the description of C. bandeirensis (Verdade et al., 2019), C. lithomimeticus (Da Silva \& Ouvernay, 2012), C. Iutzorum (Lima et al., 2010), C. rhyakonastes (Nunes-de-Almeida et al., 2016), C. brasiliensis, C. izecksoni, C. fuliginosus, C. stejnegeri (Heyer, 1983a) and C. valae (Heyer, 1983b).

\section{Abdominal flap}

Heyer (1983a) used, for the same structure "shelf" or "flap" apparently as synonyms. As previous authors (see Lima et al., 2010; Nunes-de-Almeida et al., 2016; Verdade et al., 2019) we prefer to standardize the name of this skin fold that contours the abdomen and extends over the vent tube, part of the tail, and limb bud, as an "ab- dominal flap." This structure seems to occur in tadpole of all species cycloramphids (see Bokermann, 1965, Heyer, 1983a, b; Verdade et al., 2019). The abdominal flap was not mentioned by Nunes-de-Almeida et al. (2016) for C. brasiliensis in his comparative table. Lima et al. (2010) do not mention the flap for $C$. fuliginosus; the structure is not considered in these works, although it was reported by Heyer (1983a) in the original description of the tadpoles for $C$. boraceiensis. In addition, Nunes-de-Almeida et al. (2016) referred to the abdominal flap of $C$. fuliginosus tadpoles as "shallowly bilobed or not", referring to Heyer (1983a) as the source of this information, although no such information is present in that work.

\section{General Body and head shape}

When describing body plus head shape for species of Cycloramphus several authors used the term "depressed" (Heyer, 1983a, b; Lima et al., 2010; Nunes-de-Almeida et al., 2016, Verdade et al., 2019), "very depressed" (Lima et al., 2010) or "compressed dorsoventrally" (Da Silva \& Ouvernay, 2012) but we opted for (and recommend) the use "depressed" (sensu Altig 2007; see discussion). About the body shape in lateral view, Lima et al. (2010) missed to complete their Table with information on body shape in lateral view for C. izecksohni and C. valae, although Heyer (1983a, b) has described it as "depressed". Similarly, in their comparative section, Nunes-de-Almeida et al. (2016) missed to report the body shape for C. lithomimeticus, which appears in the original description as "compressed dorsoventrally" (Da Silva \& Ouvernay, 2012).

\section{Spiracle}

The description of spiracle is particularly problematic when dealing with tadpoles of species of Cycloramphus. Some authors refer to the spiracle as "not visible" as to C. boraceiensis (Heyer, 1983a), C. stejnegeri (Heyer \& Crombie, 1979; Heyer, 1983a), and C. valae (Heyer, 1983b). Subsequently, for C. boraceiensis (Heyer et al., 1990), the opening is described only as "present" and for C. lithomi- 
meticus (Da Silva \& Ouvernay, 2012) as "single sinistral". For C. valae, C. lutzorum, C. boraceiensis, Lima et al. (2010) referred to it only as "small" and for C. izecksohni (Lima et al., 2010) as "very small". In some descriptions, in addition to referring to the size of the opening, the location has been described - e.g., "tiny and sinistral" for C. bandeirensis (Verdade et al., 2019), or "very small and sinistral" for C. izecksoni, C. fuliginosus, and C. brasiliensis (Heyer, 1983a).

Another problem appears in the work presented by Nunes-de-Almeida et al. (2016). When referring to previous work that described the tadpoles of $C$. boraceiensis, C. izecksohni and C. valae the authors failed to report the spiracle. In this case, the work was referring to the revision of Lima et al. (2010) that was based on direct observation of specimens where the spiracle is reported. When dealing with information for the spiracle of C. lithomimeticus as described by Da Silva \& Ouvernay (2012), they mistakenly reported spiracle as absent for that species. Finally, as previously reported by Verdade et al. (2019), for C. lutzorum Nunes-de-Almeida et al. (2016) referred to the spiracle as "dual lateral", wrongly indicating that in this species the tadpoles have two spiracles, a condition not reported in the original description (Lima et al., 2010). In addition, Lima et al. (2010) presented a comparative table with two tadpoles, one at stage 36 and the other at 43. At stage 43, the front limbs have already emerged from the branchial chambers, and a spiracle is not present anymore.

\section{Nostril position}

The relative position of the nostril opening, an important diagnostic character (Altig, 2007), has not always been reported. However, Lima et al. (2010) and Nunesde-Almeida et al. (2016) presented this information for C. valae and C. brasiliensis, although this data is not available in original descriptions (Heyer 1983a, b) and they do not indicate having examined voucher specimens. Again, Verdade et al. (2019) when referring to the tadpoles of C. boraceiensis, C. brasiliensis and C. izecksohni seems to misrepresent the original data reported by Heyer (1983a), as indicted anteriorly, we believe that this data was gathered from drawings of these tadpoles in the original description. We call attention to that even though it is not clear if the authors used only the data from the literature, or also included observations from vouchers. Besides, when Verdade et al. (2019) referred to the tadpoles C. boraceiensis, C. brasiliensis and C. fuliginosus in Table 2 (page 167), they reference Heyer et al. (1990); however, from this list, only C. boraceiensis was mentioned in that paper; in addition, the citation of the tadpoles C. izecksohni as described in Heyer (1983b), is also a mistake. This tadpole was described as $C$. duseni by Heyer (1983a), and posteriorly consider a synonym of C. izecksohni by Heyer (1983b).

\section{Vent tube}

The vent tube is another structure that generates confusion when published descriptions of Cycloramphus tadpoles are considered. This structure was described as "not visible" for C. boraceiensis (Heyer, 1983a; Lima et al., 2010), C. brasiliensis, (Heyer, 1983a), and C. rhyakonastes (Nunes-de-Almeida et al., 2016). It was described as "median" for C. bandeirensis (Verdade et al., 2019), C. fuliginosus, C. izecksohni, C. lutzorum, C. izecksohni, and C. valae (Heyer, 1983a, b; Lima et al., 2010), C. stejnegeri (Heyer \& Crombie, 1979; Heyer, 1983a), and finally, as "absent" for C. boraceiensis (Heyer et al., 1990). In their summary data tables, Nunes-de-Almeida et al. (2016) missed to present information on vent tubes for C. valae and C. izecksohni, which were reported by Lima et al. (2010).

\section{Meniscus}

The meniscus on the upper iris of Cycloramphus was first reported by Miranda-Ribeiro (1920) for adult individuals of $C$. dubius and $C$. semipalmatus (then in the genus Iliodiscus). Heyer (1983a) suggested this character as synapomorphy for Cycloramphus present in adults, and Verdade (2005, unpublished data) recognized as a synapomorphy for a clade that includes Cycloramphus + Zachaenus. Recently, the presence of meniscus in the tadpoles was recognized as a synapomorphy for Cycloramphidae (Colaço et al., 2020). However, probably due to ontogenetic peculiarities, the presence of this structure is rarely reported and appears only in the description of the larvae of C. bandeirensis (Verdade et al., 2019), C. lithomimeticus (Da Silva \& Ouvernay, 2012), and C. lutzorum (Lima et al., 2010).

\section{Stage determination}

In a similar way to the determining the proper developmental staging in the original paper describing the tadpole of C. boraceiensis (Heyer, 1983a), as already noticed by Verdade et al. (2019), Nunes-de-Almeida et al. (2016) reported that they used two tadpoles at stage 25 for description of tadpole of C. rhyakonastes, but the tadpole illustrated by them (Nunes-de-Almeida et al., 2016: figs. 2,3 ) shows a tadpole at stage 31.

\section{Row of keratodonts P3}

Every published illustration of the mouthparts Cycloramphus tadpoles shows the posteriormost row of keratodonts (P3) as having individual keratodonts notably smaller than those in the other rows, yet only Da Silva \& Ouvernay (2012) called attention to this feature.

\section{DISCUSSION}

Externally, the tadpole of C. boraceiensis shares features with all the exotrophic tadpoles known for the species in the genus, and with other members of exotrophic Cycloramphidae (e.g., meniscus, abdominal flap, compressed jaws sheaths, size, morphology, and position of the spiracular opening, smaller keratodonts on P3). Recognition of these features are scattered in the 
literature (Bokermann, 1965; Heyer, 1983a, b; Wassersug \& Heyer, 1983; Lima et al., 2010; Da Silva \& Ouvernay, 2012 Nunes-de-Almeida et al., 2016; Almeida-Silva et al., 2019; Moura et al., 2019; Verdade et al., 2019). The value of some of these features for the systematics of the family, observed in tadpoles, as the presence of meniscus on the upper iris, has only recently been recognized (Colaço et al., 2020). Further studies are still needed to identify characters (or character states) unique to the tadpoles of this genus. A similar concern was expressed by Lima et al., 2010 (pages 367 and 369) when critically reviewing features of the mouthparts of the tadpoles of $C$. boraceiensis. They noticed that only under proper magnification, the features under investigation could be properly observed and variation identified.

Our review of the literature on the morphology for cycloramphid tadpoles, and our compilation of these data, has revealed that aspects of the natural history and behavior of the tadpoles appear to be correlated with their unique morphology. For example, the movement of the tadpoles on the rock surfaces, using slow movements of the tail while feeding, or using the tail for jumping, as an escaping behavior (Bokermann, 1965; Wassersug \& Heyer, 1983; Altig \& McDiarmid, 1999; Rocha et al., 2002; Verdade et al., 2019). It has also been suggested that the abdominal flap plays an important role in slow locomotion while feeding and skimming over the rock and possibly represents an additional adaptation as suggested by Wassersug \& Heyer (1983) and Verdade et al. (2019).

Although it may be considered of minor implication to morphology, we felt it is important to discuss the usage of the terminology indicative of relative position that is used indiscriminately not only in the literature describing tadpole morphology. In the fifth edition of the classic Nomina Anatomica, on the initial pages ( $x$, there is a note on terminology terms indicating location and directions of parts of the body, and in its list figures Proximalis and Distalis (Kopsch, 1957). It is important to notice that all references to the usage of this terminology in the book refer to parts on the front and hindlimbs. A similar position is maintained in recent textbooks on vertebrate anatomy (e.g., Meyers, 2018: 28). In herpetology, although in the more classic work (Noble, 1931), this distinction is somewhat less precisely used, more recently, Duellman \& Trueb (1986) limit their usage to limbs. When reviewing the usage for tadpole of species of Cycloramphus, we noticed that distal is also used to refer to fins position in the tail (Heyer, 1983a, b; Lima et al., 2010; Da Silva \& Ouvernay, 2012; Nunes-de-Almeida et al., 2016; Verdade et al., 2019), we suggest that in these cases, the terms posterior and anterior, that are more accurate, should be used instead.

The problem with the descriptions of the spiracle in tadpoles of Cycloramphus species demands a short overview of the history of the study of this larval structure. The subject morphological diversity of spiracles in tadpoles and its importance to anuran evolution was first stressed by Orton (1953). In aquatic species, water enters through the mouth (partially with food; but we will not consider feeding in this review), gas exchange occurs in the gills and water exits the system via a large opening, similar to those in larval salamanders (Leiopelma), one midbody central opening (Ascaphus, Alytes, Bombina, and Discoglossus); one opening associated to the vent tube posteriorly (Microhylidae), two openings (Pipidae and Rhinophrynidae) or by one small that may open on the left or the right part of the body (most neobatrachians). Our studies on tadpoles of Cycloramphus lithomimeticus and Thoropa miliaris (Colaço \& Silva, in prep) indicates that in that species, an external tube is associated to the spiracle never develops, and the tadpoles only have a simple opening at the level of the lateral wall of the body. In addition, the transparency of the skin may render the opening hard to detect. Da Silva \& Ouvernay (2012) injected a pigmented solution on the tadpole's spiracular opening to check if the opening would flow into the branchial chamber. We suggest injecting a colorful solution on the mouth opening and observing where the liquid exits as a way to overcome this difficulty.

In the case of Cycloramphus stejnegeri (Heyer \& Crombie, 1979; Heyer, 1983a), the report that the spiracle is absent, raises another possible interpretation. The spiracle may actually be absent because of the stage of the development of the larvae in the sample (stages 30 and 31). Closure of the gill chamber may not be completed on the examined tadpoles yet. Larger samples of this species and of other species considered endotrophic, similar to the larvae of the two species of Zachaenus (B. Lutz, 1944; Almeida-Silva et al., 2019) are needed for further investigations. In summary, all exotrophic tadpoles of species of Cycloramphus must have one spiracle that does not form an external tube, and researchers must strive further to properly observe this structure.

Studies including the morphology of the vent tube, usually consider the positioning of the opening and/or its relationship with the ventral fin (see Altig \& McDiarmid, 1999 and Haas, 2003). Within cycloramphids although the morphology of this structure is similar across the taxa examined, it is highly distinctive from that of other tadpoles, and may represent a set of features unique to Cycloramphidae. For most of the investigated species of Cycloramphus, the vent tube is reported as "median", however, a few studies report it as "not visible" (Heyer, 1983a; Lima et al., 2010; Nunes-de-Almeida et al., 2016) or "absent" (Heyer et al., 1990). Clearly, this all seems related to the presence, in cycloramphid tadpoles (see Bokermann, 1965 and Heyer, 1983a, b) of the abdominal flap, which conceals the vent opening (as in Fig. 2F). To observe the vent opening one has to lift the flap with a pin. Another important characteristic of the vent tube in Cycloramphus relates to its non-association with the ventral fin, because in all species with described tadpoles there is no fin at the level of the vent.

For describing the body shape in lateral view, authors usually use the terms "depressed" (or "very depressed"), "compressed dorsoventrally" and "wider than deep", we opted (and recommend) as correct term for use "depressed" (sensu Altig, 2007). In addition, regard the "degree of flatness" (e.g., "very depressed"), without morphometric data, this information seems irrelevant. 


\section{ACKNOWLEDGMENTS} tadpoles for the species in the phenetic groups " $\mathrm{C}$. bolitoglossus" and "C. eleutherodactylus", we think it is necessary to discuss the available evidence used to justify the rationale for a group of endotrophic tadpoles as suggested by Verdade (2005). Because, till the time we wrote this report, the discussion is based on observations by Heyer \& Crombie (1979), we will first examine their statements related to the subject. Their observations are limited to a single observation presented as follows: "On the morning of 10 December, the second author found a female C. stejnegeri with 40 larvae on her back under a $15 \mathrm{~cm}$ diameter log beside a stream. [...] The larvae were very light in color, the yellow yolk being the most striking feature. [...] The close similarities of larval morphologies [they are comparing C. stejnegeri to Zachaenus parvulus (Girard) as described by B. Lutz, 1944] indicate that the larvae of C. stejnegeri are terrestrial larvae, completing metamorphosis on the nutrients from the large yolk stores." It is clear from these sentences that the authors never directly observed the development of the tadpoles till metamorphosis. Similarly, Brasileiro et al. (2007) presented data for C. faustoi Brasileiro, Haddad, Sawaya \& Sazima and inferred, based on the interpretation offered by Heyer $\&$ Crombie (1979), that the larvae of that species would also develop from the yolk only. Although not reporting the natural history of species in this group, a recent work by Verdade et al. (2019) bears some importance to this discussion. They describe the natural history of C. bandeirensis, a species endemic to the open, high grasslands of Parque Nacional do Caparaó, southeastern Brazil, at about 2,770 m elevation. This species deposits eggs under rocks, and the eggs are almost twice as large as the ones described for terrestrial breeder $C$. faustoi (Brasileiro et al., 2007), and bigger than the reported size for some other exotrophic species of family (see Bokermann, 1965; Caramaschi \& Sazima, 1984; Giaretta \& Facure, 2004). Therefore, egg size seems not be a reliable indirect indicator of developmental biology in this genus. With that, we are not discarding their interpretation, but only calling attention to the need for additional observation to confirm that those are indeed exotrophic tadpoles.

We hope that this overview of the character description of tadpoles of Cycloramphus in particular, as well as for Cycloramphidae in general, might serve as a starting point for the standardization of descriptions of tadpoles of unknown species in the future and also can call attention to the diversity of morphological information still unexplored in phylogenetic studies of the group, although some of the tadpoles here presented were in the literature as long as the beginning of the $X X^{\text {th }}$ Century (A. Lutz, 1928, 1929). We would also like to call attention to the fact that although we indicated the misconceptions of earlier studies, the efforts to construct summary comparative morphological tables (Lima et al., 2010; Nunes-de-Almeida et al., 2016; Verdade et al., 2019) are paramount for the progress towards a more precise interpretation of the data at hand.
During the development of this work G.C. received a fellowship as a PhD student, and G.L. and M.B. received MSc degree student fellowships, all from the Brazilian Coordenação de Aperfeiçoamento de Pessoal de Nível Superior (CAPES). HRS is a Conselho Nacional de Desenvolvimento Científico e Tecnológico (CNPq) fellow (306963/2018-3). We thank Adalbericles Nilton and his father Nilton Mariano for the fieldwork logistic. We are also in debt to Dr. Kevin de Queiroz, Smithsonian Curator of Amphibians \& Reptiles and M.S. Esther Langan (Collection Staff) for making the necessary arrangements, photographing and sending us images of the tadpole of $C$. boraceiensis originally used by Dr. Ronald Heyer in the species larval description. Joe Mendelson III read an early version of this manuscript and made significate suggestions that we have incorporated in the version submitted for publication. We are also deeply grateful to two reviewers that made important suggestion on the manuscript that improved considerably the presentation of this study. We also wish to thank Dr. Julia Klaczko, editor of this journal, for her additional work in copyediting the final version of the manuscript and further improving its correctness and readability.

\section{AUTHORS' CONTRIBUTIONS}

G.C., M.B, G.L. and H.R.S. contributed equally in all stages of the research that culminated in this paper. We all did field work, discussed the problem involved, contributed to photographic and figure assemblage and all the necessary work involved in the final stages of reporting our findings. All the authors reviewed and approved the final version of the paper.

\section{REFERENCES}

Almeida-Silva, D.; Rocha-Barros, V.C.0.; Ferreira, R.B. \& Verdade, V.K. 2019. The tadpole of Zachaenus carvalhoi Izecksohn, 1983 (Anura: (ycloramphidae). Zootaxa, 4668: 145-147. D01

Altig, R. 2007. A primer for the morphology of anuran tadpoles. Herpetological Conservation and Biology, 2: 71-74.

Altig, R. \& Johnston, G.F. 1989. Guilds of anuran larvae: relationships among developmental modes, morphologies, and habitats. Herpetological Monographs, Suppl. 3: 81-109. DOI

Altig, R. \& McDiarmid, R.W. 1999. Body plan: development and morphology. In: McDiarmid, R.W. \& Altig, R. (Eds.). Tadpoles, the biology of anuran larvae. Chicago, University of Chicago Press. p. 24-51.

Bittencourt-Silva, G. \& Silva, H. 2013. Insular anurans (Amphibia: Anura) of the coast of Rio de Janeiro, southeast, Brazil. Check List, 9: 225. D0I

Bokermann, W.C.A. 1965. Notas sobre as espécies de Thoropa Fitzinger (Amphibia, Leptodactylidae). Anais da Academia Brasileira de Ciências, 37: 525-537.

Brasileiro, C.A.; Haddad, C.F.B.; Sawaya, R.J. \& Sazima, I. 2007. A new and threatened island-dwelling species of Cycloramphus (Anura: (ycloramphidae) from southeastern Brazil. Herpetologica, 63(4): 501-510. 
Caramaschi, U. \& Sazima, I. 1983. Uma nova espécie de Thoropa da Serra do Cipó, Minas Gerais, Brasil (Amphibia, Leptodactylidae). Revista Brasileira de Zoologia, 2(3): 139-146. D01

Colaço, G.; Bittencourt-Silva, G.B. \& Da Silva, H.R. 2020. Can a shade shed light on the monophyly of Cycloramphidae (Lissamphibia: Anura)? Zoologischer Anzeiger, 285: 18-26. DOI

Da Silva, H.R. \& Ouvernay, D. 2012. A new species of stream-dwelling frog of the genus Cycloramphus (Anura, Cycloramphidae) from the State of Rio de Janeiro, Brazil. Zootaxa, 3407: 49-60.

Duellman, W.E. \& Trueb, L. 1986. Biology of Amphibians. Baltimore, The Johns Hopkins University Press.

Frost, D.R. 2020. Amphibian Species of the World: an Online Reference Available: http://research.amnh.org/herpetology/amphibia/index.html. Access: 04/05/2020.

Giaretta, A.A. \& Facure, K.G. 2004. Reproductive ecology and behavior of Thoropa miliaris (Spix, 1824) (Anura, Leptodactylidae, Telmatobiinae). Biota Neotropica, 4: 1-10. DOI

Gosner, K.L. 1960. A simplified table for staging anuran embryos and larvae with notes on identification. Herpetologica, 16: 183-190.

Haas, A. 2003. Phylogeny of frogs as inferred from primarily larval characters (Amphibia: Anura). Cladistics, 19: 23-89.

Haas, A. \& Das, I. 2010. Describing east malaysian tadpole diversity: Status and recommendations for standards and procedures associated with larval amphibian description and documentation. Bonner Zoologische Monographien, 57: 29-46.

Haddad, C.F. \& Sazima, I. 1989. A new species of Cycloramphus from southeastern Brazil (Amphibia: Leptodactylidae). Herpetologica, 45: 425-429.

Heyer, W.R. 1983a. Variation and systematics of frogs of the genus Cycloramphus (Amphibia, Leptodactylidae). Arquivos de Zoologia, 30: 235-339. DOI

Heyer, W.R. 1983b. Notes on the genus Cycloramphus (Amphibia: Leptodactylidae), with description of two species. Proceedings of the Biological Society of Washington, 96(3): 548-559.

Heyer, W.R. \& Crombie R.I. 1979. Natural history notes on Craspedoglossa stejnegeri and Thoropa petropolitana (Amphibia: Salientia, Leptodactylidae). Journal of the Washington Academy of Sciences, 69: $17-20$.

Heyer, W.R.; Rand, A.S.; Cruz, C.A.G.; Peixoto, 0.L.\& Nelson, C.E. 1990. Frogs of Boraceia. Arquivos de Zoologia, 31: 231-410.

Kopsch, F. 1957. Nomina Anatomica. Stuttgart, Georg Thieme Verlag.

Lima, A.M.;Garey, M.V.; Noleto, R.B.\&Verdade,V.K.2010. Natural history of the Lutz's frog Cycloramphus lutzorum Heyer, 1983 (Anura: Cycloramphidae) in the Brazilian Atlantic Forest: description of the advertisement call, tadpole, and karyotype. Journal of Herpetology, 44(3): 360-372. D0I

Lingnau, R.; Solé, M.; Dallacorte, F. \& Kwet, A. 2008. Description of the advertisement call of Cycloramphus bolitoglossus (Werner, 1897), with comments on other species in the genus from Santa Catarina, south Brazil (Amphibia, Cycloramphidae). North-Western Journal of Zoology, 4(2): 224-235.

Lutz, A. 1928. Biologie et metamorphose des Batraciens du genre Cycloramphus. Comptes Rendus Hebdomadaires des Sciences et Memoires de la Sociétè de Biologie et des ses Filiares, 98: 640.

Lutz, A. 1929. Taxonomia e biologia do gênero Cyclorhamphus. Memórias do Instituto Oswaldo Cruz, 22: 5-25. DOI

Lutz, B. 1944. Biologia e taxonomia de Zachaenus parvulus. Boletim do Museu Nacional. Nova Serie, Zoologia. Rio de Janeiro, 17: 1-66.

Lutz, B. 1947. Trends towards non-aquatic and direct development in frogs. Copeia, 1947: 242-252. D0

Lutz, B. 1948. Ontogenetic evolution in frogs. Evolution, 2: 29-39. DOI
McDiarmid, R.W. \& Altig, R. 1999. Tadpoles: the biology of anuran larvae. Chicago, University of Chicago Press.

Meyers, S. 2018. Sack and Wensing's textbook of veterinary anatomy. Missouri, Elsevier Health Sciences.

Miranda-Ribeiro, A. de. 1920. 0 genero Telmatobius já foi constatado no Brasil? Revista do Museu Paulista, 12: 261-278. D0I

Moura, P.H.A.G.; da Rocha-Alves-Jr., S.; de Souza e Sousa, D.D.G.; Correa, C.N. \& Nunes, I. 2019. Redescription of the tadpole of Thoropa taophora (Miranda-Ribeiro) (Anura: Cycloramphidae).Zootaxa, 4656:397-400. D0

Noble, G.K. 1931. The Biology of the Amphibia. McGraw-Hill Book Company, New York. DOI

Noleto, R.B.; Amaro, R.C.; Verdade, V.K.; Campos, J.R.C.; Gallego, L.F.K.; de Lima, A.M.X.; Cestari, M.M.; Kasahara, S.; Yonenaga-Yassuda, Y.; Rodrigues, M.T.; Toledo, L.F. 2011. Comparative cytogenetics of eight species of Cycloramphus (Anura, Cycloramphidae). Zoologischer Anzeiger, 250: 205-214.

Nunes-de-Almeida, C.H.L.; Zamudio, K.R. \& Toledo, L.F. 2016. The semiterrestrial tadpole of Cycloramphus rhyakonastes Heyer, 1983 (Anura, Cycloramphidae). Journal of Herpetology, 50(2): 289-294. D0I

Orton, G.L. 1953. The systematics of vertebrate larvae. Systematic Zoology, 2: 63-75. DOI

Rocha, C.F.D.; Telles, F.B.D.S.; Vrcibradic, D. \& Nogueira-Costa, P. 2018. The herpetofauna from Ilha Grande (Angra dos Reis, Rio de Janeiro, Brazil): updating species composition, richness, distribution and endemisms. Papéis Avulsos de Zoologia, 58(25): 1-12. D01

Rocha, C.F.D.; Van Sluys, M.; Bergallo, H.G. \& Alves, M.A.S. 2002. Microhabitat use and orientation to water flow direction by tadpoles of the leptodactylid frog Thoropa miliaris in southeastern Brazil. Journal of Herpetology, 36: 98-100. DOI

de Sá, F.P.; Haddad, C.F.B.; Gray, M.M.; Verdade, V.K.;Thomé, M.T.C.; Rodrigues, M.T.; Zamudio, K.R. 2019. Male-male competition and repeated evolution of terrestrial breeding in Atlantic coastal forest frogs. Evolution, 74(2): 459-475. DO|

Schulze, A.; Jansen, M.; Köhler, G. 2015. Tadpole diversity of Bolivia's lowland anuran communities: Molecular identification, morphological characterisation, and ecological assignment. Zootaxa, 4016: 1-111. DOI

Starrett, P.H. 1973. Evolutionary patterns in larval morphology. In: Vial, J.L. (Ed.). Evolutionary biology of the anurans: contemporary research on major problems. Misouri, University of Misouri Press. p. 251-271.

Tschudi, J.J. von. 1838. Classification der Batrachier mit Berücksichtigung der fossilen Thiere dieser Abtheilung der Reptilien. Neuchâtel. Petitpierre.

Verdade, V.K. 2005. Relações filogenéticas entre as espécies dos gêneros Cycloramphus Tschudi 1838 e Zachaenus Cope 1866 (Anura, Leptodactylidae). (Doctoral dissertation). Universidade de São Paulo, São Paulo.

Verdade, V.K. \& Rodrigues, M.T. 2003. A new species of Cycloramphus (Anura, Leptodactylidae) from the Atlantic Forest, Brazil. Herpetologica, 59(4): 513-518. DOI

Verdade, V.K.; Almeida-Silva, D.; Cassimiro, J. \& Rodrigues, M.T. 2019. Rediscovering Cycloramphus bandeirensis (Anura: Cycloramphidae): natural history and breeding biology of a vulnerable species with a variant reproductive mode. Phyllomedusa: Journal of Herpetology, 18: 159-175. DOI

Wassersug, R.J. \& Heyer, W.R. 1983. Morphological correlates of subaerial existence in leptodactylid tadpoles associated with flowing water. Canadian Journal of Zoology, 61(4): 761-769. D0I

Weber, L.N.; Verdade, V.K.; Salles, R.O.L.; Fouquet, A. \& Carvalho-e-Silva, S.P. 2011. A new species of Cycloramphus Tschudi (Anura: Cycloramphidae) from the Parque Nacional da Serra dos Órgãos, Southeastern Brazil. Zootaxa, 2737: 19-33. D0I 